\title{
Long-acting $\beta$-adrenoceptor agonists in the management of COPD: focus on indacaterol
}

This article was published in the following Dove Press journal:

International Journal of COPD

I I April 201 I

Number of times this article has been viewed

Jutta Beier

Kai M Beeh

insaf Respiratory Research Institute, Wiesbaden, Germany
Correspondence: Kai Michael Beeh insaf Respiratory Research Institute, Biebricher Allee 34, D-65।87

Wiesbaden, Germany

Tel +496119854410

Fax +496119854348

Email k.beeh@insaf-wi.de
Abstract: Bronchodilators are the cornerstone of severe chronic obstructive pulmonary disease (COPD) treatment to improve airflow, symptoms, exercise tolerance, and exacerbations. There is convincing evidence that regular treatment with long-acting bronchodilators is more effective and convenient than treatment with short-acting bronchodilators. Long-acting $\beta$-2-agonists include the twice-daily drugs formoterol and salmeterol and, more recently, once-daily indacaterol. Studies with head-to-head comparisons of long-acting bronchodilators are scant, but novel data from controlled trials with the once-daily $\beta(2)$-agonist indacaterol indicate superior bronchodilation and clinical efficacy of indacaterol at recommended doses over twice-daily long-acting $\beta(2)$-agonists, and at least equipotent bronchodilation compared with once-daily tiotropium. The recent therapeutic developments in COPD underscore a shift from short-acting bronchodilators with multiple dosings per day to reduced dosing frequency and prolonged duration of action, including once-daily treatment, with more consistent effects on various clinical outcomes. This review summarizes relevant clinical data for twice-daily $\beta$-2-agonists in COPD, and further focuses on novel data for once-daily indacaterol, including head-to-head comparison trials.

Keywords: COPD, bronchodilators, salmeterol, indacaterol, formoterol, tiotropium, therapy, pharmacology

\section{Background: long-acting $\beta$-agonists in the treatment of COPD}

Current guidelines recommend long-acting bronchodilators as first-line maintenance therapy for moderate, severe, and very severe chronic obstructive pulmonary disease (COPD), with a preference for inhaled medications over oral theophyllines. ${ }^{1}$ Until recently, the once-daily anticholinergic tiotropium and the twice-daily $\beta(2)$-agonists salmeterol and formoterol were the most widely used maintenance medications. Both classes of agents have been demonstrated to be effective and hold acceptable safety profiles. In December 2009, the first once-daily long-acting $\beta$-agonist indacaterol was approved by the European Medicines Agency, and indacaterol once daily was consequently introduced into the market. The availability of a once-daily inhaled $\beta$-2-agonist for the maintenance treatment of COPD somehow marks a trend in the recent therapeutic developments in COPD, indicating a shift from short-acting bronchodilators with multiple dosings per day to reduced dosing frequency and prolonged duration of action, including once-daily treatment. This change has been consistently associated with improvements in clinical outcomes of COPD patients. Alongside the introduction of new bronchodilators, longer duration of bronchodilation showed more consistent improvements in lung function and patient-centered outcomes, 
including airflow (forced expiratory volume in 1 second $\left.\left[\mathrm{FEV}_{1}\right]\right)$, hyperinflation, symptom control, dyspnea, quality of life, physical activity, and exacerbations. ${ }^{2,3}$ Recent data from large-scale clinical trials may also indicate a beneficial effect of long-acting bronchodilators on disease progression ${ }^{4}$ and even mortality in subsets of patients. ${ }^{5}$ Finally, a reduction of dosing frequency for inhaled therapies will simplify the management of COPD, ultimately leading to improved patient adherence and compliance, ${ }^{6}$ contributing to better clinical outcomes. ${ }^{7}$ The aim of this review is to summarize relevant data and landmark studies comparing the efficacy of short- versus longer-acting bronchodilators in COPD, including new data for once-daily indacaterol.

\section{Clinical benefits of twice-daily long-acting $\beta$-2-agonists in COPD}

The long-acting $\beta(2)$-agonists (LABA) formoterol and salmeterol were licensed for the treatment of COPD over a decade ago. Both drugs have a duration of action of approximately 12 hours, requiring a twice-daily dosage. ${ }^{8,9}$ Formoterol and salmeterol are more effective than short-acting bronchodilators in improving lung function $\left(\mathrm{FEV}_{1}\right),{ }^{10-13}$ with improvements in symptoms for formoterol versus ipratropium, ${ }^{10}$ but no consistent effect on exacerbations versus regular ipratropium for both. ${ }^{10,12,13}$ In a study by Rennard et al ${ }^{13}$ salmeterol 50 microgram (mcg) twice daily was also not superior to regular ipratropium in regard to improving symptoms, dyspnea, and exercise. To date, there are no conclusive data from comparative studies investigating the effects of salmeterol and formoterol head to head on relevant long-term outcomes in COPD. ${ }^{14}$ As was already known from asthma trials, formoterol has a faster onset of bronchodilator action in COPD versus salmeterol. ${ }^{15,16}$ Due to the lack of any further supporting data, current guidelines do not recommend any of theses two twice-daily LABAs over the other for the maintenance treatment of COPD.

Both formoterol and salmeterol have been extensively studied as monotherapy for COPD as control arms in the pivotal studies investigating the efficacy of inhaled corticosteroids/LABA fixed-dose combination. ${ }^{17-20}$ In these studies, LABA monotherapy was associated with numerous clinical improvements; however, as no regular short-acting bronchodilator comparator was investigated in any of these trials, the data do not allow any definite conclusion about the comparative efficacy of twice-daily versus short-acting $\beta$-agonists in COPD. Direct comparisons between twicedaily LABAs and the once-daily anticholinergic tiotropium in patients with COPD have generally been short term, with one report of two combined studies of 6 months' duration. ${ }^{21}$ In comparison with salmeterol, tiotropium provided greater improvements in lung function and symptoms, ${ }^{21,22}$ whereas there was only a numerical reduction in exacerbations compared with salmeterol. A subsequent 12-week randomized, double-blind study versus salmeterol documented superior bronchodilation during 12-hour testing. ${ }^{23}$ Formoterol provided similar bronchodilation to tiotropium 12 hours after inhalation, but the magnitude of effect was higher during the first 2 hours post-dose, consistent with a faster onset of bronchodilator action for formoterol. ${ }^{24}$ A 6-month study comparing the combination of tiotropium and formoterol with single components and placebo reported no differences in outcomes of formoterol monotherapy versus tiotropium. ${ }^{25}$ In general, the evidence level has not shown clear distinctions between twice-daily LABAs and tiotropium on more clinically oriented outcomes. Currently, an ongoing large-scale study will directly compare the effect of tiotropium with salmeterol on COPD exacerbations. ${ }^{26}$

\section{Indacaterol: once-daily $\beta$-2-agonist with 24-hour duration of action}

In December 2009, the once-daily LABA indacaterol was approved for the maintenance treatment of COPD in the European Union at a recommended dose of $150 \mathrm{mcg}$ once daily and a maximum dose of $300 \mathrm{mcg}$ once daily. Indacaterol is a partial $\beta(2)$-agonist with high intrinsic efficacy at the receptor level. Unlike other partial agonists, it does not exhibit antagonistic behaviour in the presence of isoprenaline ("near full agonist"). ${ }^{27}$ Potency and intrinsic efficacy have been demonstrated in various models, including recombinant receptors, guinea pig trachea, isolated human bronchus, and human lung slices, with a selectivity ratio for indacaterol of 28 and 22 against $\beta_{1}$ and $\beta_{3}$ receptors. ${ }^{27-29}$ In these studies, a fast onset of action and longer duration of action versus formoterol and salmeterol were also demonstrated. Although the prolonged duration of action of indacaterol versus other lipophilic $\beta(2)$ agonists like salmeterol can potentially be explained by the higher affinity of indacaterol to lipid raft domains within the membrane, ${ }^{30}$ its fast onset of action is related to the high intrinsic efficacy at the receptor level. ${ }^{31}$ Pharmacokinetic data taken during multiple-dose studies of indacaterol $400 \mathrm{mcg}$ or $800 \mathrm{mcg}$ once daily for 14 days demonstrated rapid absorption and a mean elimination half life of $>30$ hours, whereas, in a single-dose study, doses between $600 \mathrm{mcg}$ and $2000 \mathrm{mcg}$ were rapidly absorbed with maximum serum concentrations reached within 15 minutes. ${ }^{32,33}$ Steady state after inhalation was reached within 12 days of once-daily dosing. ${ }^{34}$ 


\section{Clinical data for once-daily indacaterol}

At the time of writing, several thousands of patients with COPD have received indacaterol in various doses for up to 52 weeks of treatment during the Phase II and III clinical program. Early clinical studies suggested that indacaterol produces rapid (within 5 minutes) and sustained (for at least 24 hours) bronchodilation in patients with various degrees of airflow obstruction. ${ }^{35,36}$ Further, a study by Beier et $\mathrm{al}^{37}$ confirmed that a single dose of indacaterol $300 \mathrm{mcg}$ provided a greater effect on airflow obstruction and resting hyperinflation (inspiratory capacity) in patients with COPD than twice-daily formoterol $12 \mathrm{mcg} .{ }^{37}$

In the randomized, controlled Phase III COPD trials investigating the effects of treatment with $150 \mathrm{mcg}$ or $300 \mathrm{mcg}$ indacaterol once daily for up to 52 weeks' duration, indacaterol effectively improved numerous clinical outcomes over placebo, including trough $\mathrm{FEV}_{1}$, symptom control, dyspnea, quality of life, and exacerbations..$^{38-40}$ However, the Phase III studies also incorporated several active comparator drugs, including the twice-daily LABAs formoterol and salmeterol and the once-daily anticholinergic tiotropium.

In a 2-week, open-label comparison study of indacaterol $300 \mathrm{mcg}$ once daily versus salmeterol $50 \mathrm{mcg}$ twice daily, trough $\mathrm{FEV}_{1}$ on day 14 for indacaterol was $90 \mathrm{~mL}$ higher than for salmeterol $(P=0.011)$. This was also accompanied by superior improvements in resting inspiratory capacity across a full 24-hour assessment period on day 14 , reaching statistical significance at most post-dose timepoints. ${ }^{41}$

Compared with salmeterol $50 \mathrm{mcg}$ twice daily, indacaterol $150 \mathrm{mcg}$ once daily was superior in improving trough $\mathrm{FEV}_{1}$ after 12 weeks and 26 weeks (differences $+60 \mathrm{~mL}$ and $+70 \mathrm{~mL}$, respectively, $P<0.001$ ), quality of life, dyspnea, and need for additional rescue medication in a randomized, double-blind, comparison study. ${ }^{39}$ Superior clinical efficacy of $150 \mathrm{mcg}$ indacaterol once daily versus salmeterol twice daily was also confirmed in a double-blind, 12-week comparison study. ${ }^{42}$

A long-term comparison of indacaterol $300 \mathrm{mcg}$ once daily over 52 weeks showed superior effects of indacaterol over formoterol $12 \mathrm{mcg}$ twice daily on lung function (trough $\mathrm{FEV}_{1}$ ), dyspnea, and rescue medication usage..$^{43}$ In a pooled analysis, it appeared that $150 \mathrm{mcg}$ indacaterol once daily also provided superior benefits on trough $\mathrm{FEV}_{1}$ after 12 weeks of treatment versus formoterol $12 \mathrm{mcg}$ twice daily, regardless of concomitant use of inhaled corticosteroids. ${ }^{44}$

During a 26-week randomized comparison trial, indacaterol $150 \mathrm{mcg}$ or $300 \mathrm{mcg}$ once daily was compared with placebo and open-label tiotropium $18 \mathrm{mcg}$ once daily over 26 weeks. ${ }^{45}$ Trough FEV ${ }_{1}$ at week 12 increased versus placebo by $180 \mathrm{~mL}$ with both indacaterol doses and by $140 \mathrm{~mL}$ with tiotropium (all $P<0.001$ ). At week 12 and week 26, there were also significant treatment differences between indacaterol at both doses and tiotropium $(+40-50 \mathrm{~mL}$ favoring indacaterol), when tested for superiority $(P<0.05$, all comparisons), although the interpretability of these data may be complicated by the fact that tiotropium was administered open label. Further clinically relevant improvements were observed with indacaterol versus placebo for dyspnea and health-related quality of life.

However, a fully (third-party) blinded, randomized, double-blinded, crossover clinical comparison of the effects of indacaterol $150 \mathrm{mcg}$ and $300 \mathrm{mcg}$ once daily versus tiotropium $18 \mathrm{mcg}$ once daily or matching placebo proved noninferiority for both doses of indacaterol in regard to trough $\mathrm{FEV}_{1}$ after 14 days of treatment compared with tiotropium 18 mcg, with mean trough $\mathrm{FEV}_{1}$ values again favoring indacaterol $150 \mathrm{mcg}(+50 \mathrm{~mL}$ vs tiotropium) and $300 \mathrm{mcg}$ ( $+30 \mathrm{~mL}$ vs tiotropium). Although superiority was not proven statistically, these data nevertheless altogether indicate that indacaterol provides at least equipotent bronchodilation after 14 days compared with tiotropium. ${ }^{46}$

Finally, a further blinded comparison of indacaterol $150 \mathrm{mcg}$ with tiotropium $18 \mathrm{mcg}$ once daily showed comparable effects on trough $\mathrm{FEV}_{1}$ after 12 weeks $(1.44 \mathrm{~L}$ for indacaterol vs $1.43 \mathrm{~L}$ for tiotropium, $P<0.001$ for noninferiority), with additional benefits for indacaterol over tiotropium in regard to dyspnea, health-related quality of life, and rescue medication use. ${ }^{47}$

\section{Pooled analyses and subgroups}

Pooled analyses, including some of the aforementioned clinical trials, were published during the American Thoracic Society 2010 annual meeting. These data demonstrated that indacaterol $150 \mathrm{mcg}$ or $300 \mathrm{mcg}$ once daily administered over 3-6 months provides significant and clinically meaningful improvement of symptoms, health-related quality of life, rescue medication use, and exacerbation rates in moderate-to-severe COPD patients. ${ }^{48,49}$ Further, it was shown that longer-term beneficial effects of indacaterol were not dependent on age, concomitant inhaled corticosteroid use, and baseline bronchodilator reversibility. ${ }^{44,50,51}$

\section{Safety}

Safety studies with indacaterol addressed the occurrence of adverse events and serious adverse events, cardiovascular 
safety, and known class effects from $\beta$-agonists due to systemic absorption of drug, potentially leading to tachycardia, palpitations, changes in electrocardiogram parameters (eg, QT prolongation), hypokalemia, increase in blood glucose levels, and adverse events like tremor or headache.

\section{Phase II studies}

Three multiple-dose Phase II trials primarily evaluating safety and tolerability of indacaterol have as yet been fully published, two in asthma ${ }^{52,53}$ and one in COPD. ${ }^{54}$ These three trials incorporated a treatment duration of 28 days. However, trials used different dosages of indacaterol, and indacaterol was delivered in a multiple-dose dry powder inhaler, which differs from the currently marketed singledose dry powder inhaler device. In studies by Yang et $\mathrm{al}^{53}$ and Beier et $\mathrm{al}^{54}$ indacaterol at once-daily doses of $400 \mathrm{mcg}$ and $800 \mathrm{mcg}$ from single-dose dry powder inhaler was used, whereas Chuchalin et al ${ }^{52}$ evaluated indacaterol at dosages of $200 \mathrm{mcg}, 400 \mathrm{mcg}$, or $600 \mathrm{mcg}$ daily.

In all studies, the overall incidence of adverse events was similar for active treatment and placebo groups, and there was no dose-related increase in the incidence of adverse events. The most common adverse event associated with indacaterol use was cough, which was reported in $16.9 \%$ and $15.3 \%$ of patients in the indacaterol $400 \mathrm{mcg}$ and $800 \mathrm{mcg}$ groups, respectively, in the study by Yang et al; ${ }^{53}$ in $8.1 \%$, $17.1 \%$, and $10.3 \%$ of patients in the indacaterol $600 \mathrm{mcg}$, $400 \mathrm{mcg}$, and $200 \mathrm{mcg}$ groups, respectively, in the study by Chuchalin et al, ${ }^{52}$ and in $14.7 \%$ and $28.4 \%$ of patients in the $400 \mathrm{mcg}$ and $800 \mathrm{mcg}$ groups, respectively, in the study by Beier et al. ${ }^{54}$ For the typical class effects of $\beta$-agonists, only modest effects were observed. Although Yang et $\mathrm{al}^{53}$ reported small changes in postdose serum potassium and glucose levels of asthmatic patients exposed to indacaterol $400 \mathrm{mcg}$ or $800 \mathrm{mcg}$, no effect on these parameters was observed in the study by Beier et $\mathrm{al}^{54}$ using the same doses in COPD patients. In the study by Chuchalin et $\mathrm{al}^{52}$ in asthmatics, no effect of once-daily indacaterol $200 \mathrm{mcg}, 400 \mathrm{mcg}$, and $600 \mathrm{mcg}$ on potassium and glucose levels was observed. In this study, there were also no changes in pulse rate, blood pressure, or mean QTc interval after 28 days' exposure to indacaterol. However, there was a small, statistically significant increase of the QTc interval $(8.9 \mathrm{~ms})$ and pulse rate $(4.9$ beats per minute) with the $800 \mathrm{mcg}$ dose $(\mathrm{n}=59)$ on day 28 in the study by Yang et $\mathrm{al}^{53}$ but these changes were numerically small and not clinically significant. Again, none of these effects was observed by Beier et $\mathrm{al}^{54}$ in the study using indacaterol $400 \mathrm{mcg}$ and $800 \mathrm{mcg}$ once daily in COPD patients.

The effect of indacaterol at dosages up to $600 \mathrm{mcg}$ once daily over 14 days on QTc values has been studied in a thorough QT study in healthy subjects. All doses of indacaterol had no effect on mean QTc values, and changes were within the regulatory safety margin. ${ }^{55}$ Finally, inhalation of supratherapeutic single doses of indacaterol up to $3000 \mathrm{mcg}$ in COPD patients revealed only minor systemic effects. ${ }^{56}$

\section{Phase III trials}

In a 12 -week trial investigating $150 \mathrm{mcg}$ indacaterol versus placebo for 12 weeks, ${ }^{40}$ the incidence of any adverse event was comparable for indacaterol and placebo (indacaterol $\mathrm{n}=104,49.3 \%$; placebo $\mathrm{n}=96,46.8 \%$ ). There were no cardiac safety issues. No patient had a prolongation of the QTc interval beyond $500 \mathrm{msec}$ absolute or $>60 \mathrm{msec}$ increase from baseline, and no increase of pulse rate was observed.

During a further 26-week comparison trial, the frequency of adverse events was comparable for indacaterol $150 \mathrm{mcg}$ and $300 \mathrm{mcg}$ with open-label tiotropium and placebo. Similarily, the overall proportion of patients with an increase in QTcF of 30-60 msec or $>60 \mathrm{msec}$ was low and comparable with tiotropium and placebo. ${ }^{57}$

Finally, during the large-scale comparator trial with indacaterol $300 \mathrm{mcg}$ and $600 \mathrm{mcg}$ versus formoterol $12 \mathrm{mcg}$ twice daily and placebo over 1 year, adverse events and severe adverse events occurred in a similar frequency for both doses of indacaterol and placebo. Again, the overall proportion of patients with an increase in QTcF of 30-60 msec or $>60$ msec was low and comparable with formoterol and placebo. Further, indacaterol at both doses did not affect mean serum potassium at week 52, mean QTc values, or average pulse rate. ${ }^{43}$

Chapman et $\mathrm{al}^{38}$ recently reported on the safety of indacaterol $150 \mathrm{mcg}$ and $300 \mathrm{mcg}$ once daily versus placebo during the 26-week extension phase of the 26-week openlabel tiotropium comparison study, thereby providing data over a total duration of 52 weeks. In their analysis, adverse events occurred in $76 \%, 77 \%$, and $68 \%$ of subjects receiving indacaterol $150 \mu \mathrm{g}, 300 \mu \mathrm{g}$, and placebo, respectively, whereas serious adverse events occurred in $10.4 \%, 12.3 \%$, and $10.5 \%$, respectively. There were no clinically significant effects with indacaterol at both doses on QTc interval or potassium or glucose levels.

Finally, Worth et $\mathrm{al}^{58}$ specifically reported on the cardioand cerebrovascular safety of indacaterol $150 \mathrm{mcg}$ and 
$300 \mathrm{mcg}$ once daily versus placebo and comparator drugs salmeterol, formoterol, and tiotropium using Antiplatelet Trialists' Collaboration criteria for cardio-/cerebrovascular adverse events. Safety data were pooled from three clinical trials. ${ }^{39,43,45}$ The risk of cardio-/cerebrovascular events was not significantly increased for indacaterol at both doses versus placebo, and the incidence of notable QTc interval changes ( $>60 \mathrm{~ms}$ versus baseline) was low with all treatments. In a subgroup of patients analyzed by Holter monitoring, there was no relevant effect of indacaterol versus placebo on the development of arrhythmias. Mortality was numerically lower with all active treatments than with placebo, with a $70 \%$ lower relative risk with indacaterol at both doses versus placebo $(P=0.054)$.

In light of the approved recommended dose of $150 \mathrm{mcg}$ and a maximal recommended dose of $300 \mathrm{mcg}$ once daily, the overall safety data indicate a favorable tolerability profile and a broad therapeutic window for indacaterol.

\section{Summary}

Bronchodilators are the cornerstone of treatment for all COPD severity stages, with a central role in the symptomatic management of COPD. They are given on an as-needed basis or on a regular basis to prevent or reduce symptoms and exacerbations. The principal inhaled bronchodilator treatments are $\beta(2)$-agonists and anticholinergics, used alone or in combination. There is broad evidence that regular treatment with long-acting bronchodilators is more effective and convenient than treatment with short-acting bronchodilators. New data from trials with the novel once-daily $\beta(2)$-agonist indacaterol indicate superior bronchodilation and clinical efficacy over twice-daily LABAs salmeterol and formoterol and at least equipotent bronchodilation as once-daily tiotropium. Therapeutic developments in COPD indicate a change shift from short-acting bronchodilators with multiple dosings per day to reduced dosing frequency and prolonged duration of action, including once-daily treatment.

\section{Disclosure}

JB and KMB have both participated as speakers in scientific meetings or courses organized and financed by various pharmaceutical companies (AstraZeneca, Almirall, GSK, Boehringer, Novartis, Pfizer, Takeda) in 2006-2011. JB and KMB have also been reimbursed for travel expenses for attending and presenting at scientific conferences by various pharmaceutical companies. The institution where JB and KMB are currently employed has received reimbursement for design and performance or participation in single or multi-centre clinical trials in 2004-2011 from various companies (Almirall, Altana, AstraZeneca, Boehringer Ingelheim, Cytos, Novartis, GSK, Revotar Biopharmaceuticals, EpiGenesis, Corus Pharma, Merck Sharp \& Dohme, Fujisawa, Pfizer, Medapharma). JB and KMB have received compensations for serving on advisory boards for AstraZeneca, Almirall, Cytos, Boehringer Ingelheim, Novartis, and Revotar AG from 2006-2011.

\section{References}

1. Global Initiative for Chronic Obstructive Lung Disease. Global strategy for the diagnosis, management, and prevention of chronic obstructive pulmonary disease: 2008 update. http://www.goldcopd.com/. Accessed March 21, 2011.

2. Sin DD, MacAlister FA, Man SFP, Anthonisen NR. Contemporary management of chronic obstructive pulmonary disease. JAMA. 2003; 290:2301-2312.

3. Tashkin DP, Cooper CB. The role of long-acting bronchodilators in the management of stable COPD. Chest. 2004;125:249-259.

4. Decramer M, Celli B, Kesten S, et al. Effect of tiotropium on outcomes in patients with moderate chronic obstructive pulmonary disease (UPLIFT): a prespecified subgroup analysis of a randomised controlled trial. Lancet. 2009;374:1171-1178.

5. Celli B, Decramer M, Kesten S, et al. Mortality in the 4-year trial of tiotropium (UPLIFT) in patients with chronic obstructive pulmonary disease. Am J Respir Crit Care Med. 2009;180:948-955.

6. Bourbeau J, Bartlett SJ. Patient adherence in COPD. Thorax. 2008;63: 831-838.

7. Vestbo J, Anderson JA, Calverley PMA, et al. Adherence to inhaled therapy, mortality and hospital admission in COPD. Thorax. 2009;64: 939-943.

8. Cazzola M, Santangelo G, Piccolo A, et al. Effect of salmeterol and formoterol in patients with chronic obstructive pulmonary disease. Pulm Pharmacol. 1994; 7:103-107.

9. Cazzola M, Matera MG, Santangelo G, et al. Salmeterol and formoterol in partially reversible severe chronic obstructive pulmonary disease: a dose-response study. Respir Med. 1995;89:357-362.

10. Dahl R, Greefhorst LA, Nowak D, et al. Inhaled formoterol dry powder versus ipratropium bromide in chronic obstructive pulmonary disease. Am J Respir Crit Care Med. 2001;164:778-784.

11. Matera MG, Cazzola M, Vinciguerra A, et al. A comparison of the bronchodilating effects of salmeterol, salbutamol and ipratropium bromide in patients with chronic obstructive pulmonary disease. Pulm Pharmacol. 1995;8:267-271.

12. Mahler DA, Donohue JF, Barbee RA, et al. Efficacy of salmeterol xinafoate in the treatment of COPD. Chest. 1999;115:957-965.

13. Rennard SI, Anderson W, ZuWallack R, et al. Use of a long-acting inhaled beta2-adrenergic agonist, salmeterol xinafoate, in patients with chronic obstructive pulmonary disease. Am J Respir Crit Care Med. 2001;163:1087-1092.

14. Cote C, Pearle JL, Sharafkhaneh A, Spangenthal S. Faster onset of action of formoterol versus salmeterol in patients with chronic obstructive pulmonary disease: a multicenter, randomized study. Pulm Pharmacol Ther. 2009;22:44.

15. Bouros D, Kottakis J, Le Gros V, et al. Effects of formoterol and salmeterol on resting inspiratory capacity in COPD patients with poor FEV(1) reversibility. Curr Med Res Op. 2004;20:581-586.

16. Celik G, Kayacan O, Beder S, Durmaz G. Formoterol and salmeterol in partially reversible chronic obstructive pulmonary disease: a crossover, placebo-controlled comparison of onset and duration of action. Respiration. 1999;66:434-439. 
17. Szafranski W, Cukier A, Ramirez A, et al. Efficacy and safety of budesonide/formoterol in the management of chronic obstructive pulmonary disease. Eur Respir J. 2003;21:74-81.

18. Calverley PMA, Boonsawat W, Cseke Z, et al. Maintenance therapy with budesonide and formoterol in chronic obstructive pulmonary disease. Eur Respir J. 2003;22:912-919.

19. Calverley PMA, Anderson JA, Celli BR, et al. Salmeterol and fluticasone propionate and survival in chronic obstructive pulmonary disease. N Engl J Med. 2007;356:775-789.

20. Calverley PMA, Pauwels R, Vestbo J, et al. Combined salmeterol and fluticasone in the treatment of chronic obstructive pulmonary disease: a randomised controlled trial. Lancet. 2003;361:449-456.

21. Brusasco V, Hodder R, Miravitlles M, et al. Health outcomes following treatment for six months with once daily tiotropium compared with twice daily salmeterol in patients with COPD. Thorax. 2003;58:399-404.

22. Donohue JF, Van Noord JA, Langley SJ, et al. Superior bronchodilation of once daily tiotropium compared to twice daily salmeterol in patients with COPD. Eur Respir J. 2001;18:26s.

23. Briggs JDD, Covelli H, Lapidus R, et al. Improved daytime spirometric efficacy of tiotropium compared with salmeterol in patients with COPD. Pulm Pharmacol Ther. 2005;18:397-404.

24. Richter K, Stenglein S, Mocke M, et al. Onset and duration of action of formoterol and tiotropium in patients with moderate to severe COPD. Respiration. 2006;73:414-419.

25. Vogelmeier C, Kardos P, Harar Si, et al. Formoterol mono- and combination therapy with tiotropium in patients with COPD: a 6-month study. Respir Med. 2008;102:1511-1520.

26. Beeh KM, Hederer B, Glaab T, et al. Study design considerations in a large COPD trial comparing effects of tiotropium with salmeterol on exacerbations. Int J COPD. 2009;4:119-124.

27. Naline E, Trifilieff A, Fairhurst RA, et al. Effect of indacaterol, a novel long-acting beta2-agonist, on isolated human bronchi. Eur Respir J. 2007;29:575-281.

28. Battram C, Charlton SJ, Cuenoud B, et al. In vitro and in vivo pharmacological characterization of 5-[(R)-2-(5,6-diethyl-indan-2-ylamino)1-hydroxy-ethyl]-8-hydroxy-1H-quinolin-2-one (indacaterol), a novel inhaled beta(2) adrenoceptor agonist with a 24-h duration of action. J Pharmacol Exp Ther. 2006;317:762-770.

29. Sturton RG, Trifilieff A, Nicholson AG, Barnes PJ. Pharmacological characterization of indacaterol, a novel once daily inhaled beta 2 adrenoceptor agonist, on small airways in human and rat precision cut slices. J Pharmacol Exp Ther. 2008;324:270-275.

30. Lombardi D, Cuenoud B, Kraemer SD. Lipid membrane interactions of indacaterol and salmeterol: do they influence their pharmacology properties? Eur J Pharm Sci. 2009;38:533-547.

31. Rosethorne E, Turner R, Fairhurst R, Charlton S. Efficacy is a contributing factor to the clinical onset of bronchodilation of inhaled beta(2)adrenoceptor agonists. Naunyn Schmiedebergs Arch Pharmacol. 2010; 382:255-263.

32. Tarral A, Fauchoux N, Knight H, et al. Safety and tolerability of multipledose indacaterol, a novel-2-agonist, in patients with mild asthma. Eur Respir J. 2005;26(Suppl 49):253s.

33. Duvauchelle T, Elharrar B, Knight H, et al. Single-dose indacaterol, a novel 24-hour-2-agonist, is well tolerated in patients with mild asthma. Eur Respir J. 2005;26(Suppl 49):253s.

34. Perry S, Woessner R, Kaiser G, et al. Pharmakokinetics of indacaterol after single and multiple inhaled doses. Am J Respir Crit Care Med. 2010;181:A4420.

35. Rennard S, Bantje T, Centanni S, et al. A dose-ranging study of indacaterol in obstructive airways disease, with a tiotropium comparison. Respir Med. 2008;102:1033-1044.

36. Beeh KM, Derom EY, Kanniess F, et al. Indacaterol, a novel once-daily 2-agonist, provides sustained 24-hour bronchodilator efficacy in asthma. Eur Respir J. 2007;29:871-878.
37. Beier J, Beeh KM, Pascoe S, et al. Bronchodilator effects of indacaterol and formoterol in patients with COPD. Pulm Pharmacol Ther. 2009; 22:492-496.

38. Chapman KR, Rennard SI, Dogra A, et al. Long-term safety and efficacy of indacaterol, a novel long-acting \{beta\}2-agonist, in subjects with COPD: a randomized, placebo-controlled study. Chest. Feb 24, 2011. [Epub ahead of print].

39. Kornmann O, Dahl R, Centanni S, et al. Once-daily indacaterol versus twice-daily salmeterol for COPD: a placebo-controlled comparison. Eur Respir J. 2011;37:273-279.

40. Feldman G, Siler T, Prasad N, et al. Efficacy and safety of indacaterol $150 \mu \mathrm{g}$ once-daily in COPD: a double-blind, randomised, 12-week study. BMC Pulmonary Medicine. 2010;10:11.

41. LaForce C, Aumann J, de Teresa Parreno L, et al. Sustained 24-hour efficacy of once daily indacaterol $(300 \mathrm{mcg})$ in patients with chronic obstructive pulmonary disease: a randomized, crossover study. Pulm Pharmacol Ther. 2011;24:162-168.

42. Korn S, Kerwin E, Atis S, et al. Indacaterol once-daily provides superior efficacy to salmeterol twice-daily in COPD: a 12-week study. Respir Med. 2011. In press, corrected proof.

43. Dahl R, Chung KF, Buhl R, et al. Efficacy of a new once-daily longacting inhaled beta2-agonist indacaterol versus twice-daily formoterol in COPD. Thorax. 2010;65:473-479.

44. Donohue JF, Decramer M, Owen R, et al. Indacaterol provides significant bronchodilation in patients with chronic obstructive pulmonary disease irrespective of concomitant inhaled corticosteroid use. Am J Respir Crit Care Med. 2010;181:A4438.

45. Donohue JF, Fogarty C, Lotvall J, et al. Once-daily bronchodilators for chronic obstructive pulmonary disease: indacaterol versus tiotropium. Am J Respir Crit Care Med. 2010;182:155-162.

46. Vogelmeier C, Ramos-Barbon D, Jack D, et al. Indacaterol provides 24-hour bronchodilation in COPD: a placebo-controlled blinded comparison with tiotropium. Respiratory Research. 2010;11(1):135.

47. Dunn LJ, Buhl R, Lassen C, et al. Blinded 12-week comparison of oncedaily indacaterol and tiotropium in COPD. Chest. 2010;138:719A.

48. Kleerup E, Williams J, Yegen U, et al. The effect of indacaterol once-daily on health-related quality of life, symptoms and rescue medication use in moderate-to-severe chronic obstructive pulmonary disease: pooled analysis of six month data. Am J Respir Crit Care Med. 2010;181: A4429.

49. Siler T, Williams J, Yegen U, et al. The effect of once-daily indacaterol on health-related quality of life, rescue medication use, and exacerbation rates in patients with moderate-to-severe COPD: a pooled analysis of three months of treatment. Am J Respir Crit Care Med. 2010;181: A4430.

50. Mahler DA, Buhl R, Owen R, et al. Indacaterol provides effective bronchodilation in patients with chronic obstructive pulmonary disease irrespective of patient age ( $<65$ or $>65$ years). Am J Respir Crit Care Med. 2010;181:A4456.

51. Kleerup E, D’Urzo A, Owen R, et al. Once-daily indacaterol provides significant bronchodilation in chronic obstructive pulmonary disease patients irrespective of baseline reversibility. Am J Respir Crit Care Med. 2010;181:A4439.

52. Chuchalin A, Tsoi AN, Richter K, et al. Safety and tolerability of indacaterol in asthma: a randomized, placebo-controlled 28-day study. Respir Med. 2007;101:2065-2075.

53. Yang WH, Martinot JB, Pohunek P, et al. Tolerability of indacaterol, a novel once-daily 2-agonist, in patients with asthma: a randomized, placebo-controlled, 28-day safety study. Ann Allergy Asthma Immunol. 2007;99:555-561.

54. Beier J, Chanez P, Martinot JB, et al. Safety, tolerability and efficacy of indacaterol, a novel once-daily 2-agonist, in patients with COPD: a 28-day randomised, placebo-controlled clinical trial. Pulm Pharmacol Ther. 2007;20:740-749. 
55. Khindri S, Sabo R, Harris S, et al. Cardiac safety of indacaterol - no clinical effect on QT interval in healthy subjects. Eur Respir J. 2009; 34(Suppl 53):P2031.

56. Pascoe S, Reynolds C, Pleskow W, et al. Safety, tolerability and pharmacokinetics of single escalating doses of indacaterol, a once-daily beta2agonist bronchodilator, in subjects with COPD. Int J Clin Pharmacol. 2011;49:153-161.
57. Worth H, Kleerup E, Iqbal A, et al. Safety and tolerability of indacaterol once-daily in COPD patients versus placebo and tiotropium: a 26-week study Eur Respir J. 2009;34(Supp1 53):P2030.

58. Worth H, Chung KF, Felser JM, et al. Cardio- and cerebrovascular safety of indacaterol vs formoterol, salmeterol, tiotropium and placebo in COPD. Respir Med. 2011;105:571-579.

International Journal of COPD

\section{Publish your work in this journal}

The International Journal of COPD is an international, peer-reviewed journal of therapeutics and pharmacology focusing on concise rapid reporting of clinical studies and reviews in COPD. Special focus is given to the pathophysiological processes underlying the disease, intervention programs, patient focused education, and self management protocols.

\section{Dovepress}

This journal is indexed on PubMed Central, MedLine and CAS. The manuscript management system is completely online and includes a very quick and fair peer-review system, which is all easy to use. Visit $\mathrm{http}: / /$ www.dovepress.com/testimonials.php to read real quotes from published authors.

Submit your manuscript here: http://www.dovepress.com/international-journal-of-copd-journal 